\title{
EXPLORING THE FEASIBILITY OF MOBILE MULTILINGUAL ELECTRONIC MEETINGS
}

\author{
Shilpa Balan, University of Mississippi, sbalan@bus.olemiss.edu \\ Milam Aiken, University of Mississippi, maiken@bus.olemiss.edu \\ Bidyut Hazarika, University of Mississippi, bhazarika@bus.olemiss.edu
}

\begin{abstract}
Previous research has shown that groups can exchange opinions in cellular meetings using smart devices, but no studies have compared these meetings with more traditional, face-to-face electronic meetings. Further, cellular meetings have not yet been conducted using multiple languages. In this paper, we compare groups exchanging Spanish and German comments using Web-based software with and without PDA emulators. Results show that multilingual meetings with smart devices are feasible, but desktop PC electronic meetings are still considered more useful, the software is easier to use, and translations are more comprehensible. However, this difference is not significant.
\end{abstract}

Key words: Group Support System, Electronic meetings, Cellular, Machine translation, Usability, Smart devices

\section{INTRODUCTION}

Half the world's population has access to cellular phones [22], and by 2013, cellular phones will overtake PCs as the most common Web access device worldwide [20]. As this base of technological infrastructure grows, more business activities can be conducted over the new medium. For example, electronic meetings conducted via smart devices have the potential to improve the productivity of organizations. A discussion might need to be held at the spur of the moment with people in different locations, on the move, without access to a desktop PC. Thus, Internet-enabled smart devices are a natural medium for collaboration.

In addition, with the increasing need to communicate internationally, more discussions will need to be interpreted or translated. However, it is difficult, if not impossible, for human interpreters to provide this service if group members are moving in different locations. Electronic meetings with integrated machine translation on Internet-enabled smart devices might be able to overcome this problem.

Several cellular meetings using a single language have already been conducted $[10,11,16,25,31,32,33]$. However, to our knowledge, no studies have compared this usage with a more traditional electronic meeting system based upon desktop computers. In addition, no such study has investigated multilingual translation over smart devices.

In this paper, we attempt to determine the relative differences in comprehension, ease-of-use, and usability between a multilingual meeting conducted using a Microsoft Pocket PC emulator and a meeting conducted with a desktop PC with Microsoft Windows 7, both running Web-based discussion software on Microsoft Internet Explorer 7. First, we provide a background on multilingual meetings and describe the program that is able to provide support for them over the Web. Next, we detail findings from an experiment comparing PDA use with desktop use, and we conclude with limitations and directions for future research.

\section{MULTILINGUAL MEETINGS}

An electronic meeting system (also known as a group support system or simply groupware) is a network of computers that enables group members to share, vote, and collaborate in a face-to-face or distributed environment [26]. As the world grows more interconnected, there is an increasing need for multilingual groups to engage in discussions. Because traditional, oral meetings with human interpreters suffer from several problems including a lack of anonymity, the need to take turns speaking, and the cost of interpretation, electronic meetings are now being conducted with integrated machine translation [2]. With this new technology, groups of up to 40 people have used 40 different languages at once successfully [6]. 
Volume XII, No. 1, pp. 16-22, 2011

Polyglot is an example of this technology that allows group members to exchange comments in any of 57 different languages simply and quickly [4, 7]. Using this Web-based software, a comment is typed on one page, a button is clicked to translate, and the group's comments are shown on another page translated to the participant's language of choice. For example, Figure 1 shows a group discussion about the parking problem on campus at a university in the southern region of the United States translated to German.

Figure 1: User reading meeting comments in German with a desktop computer Web browser

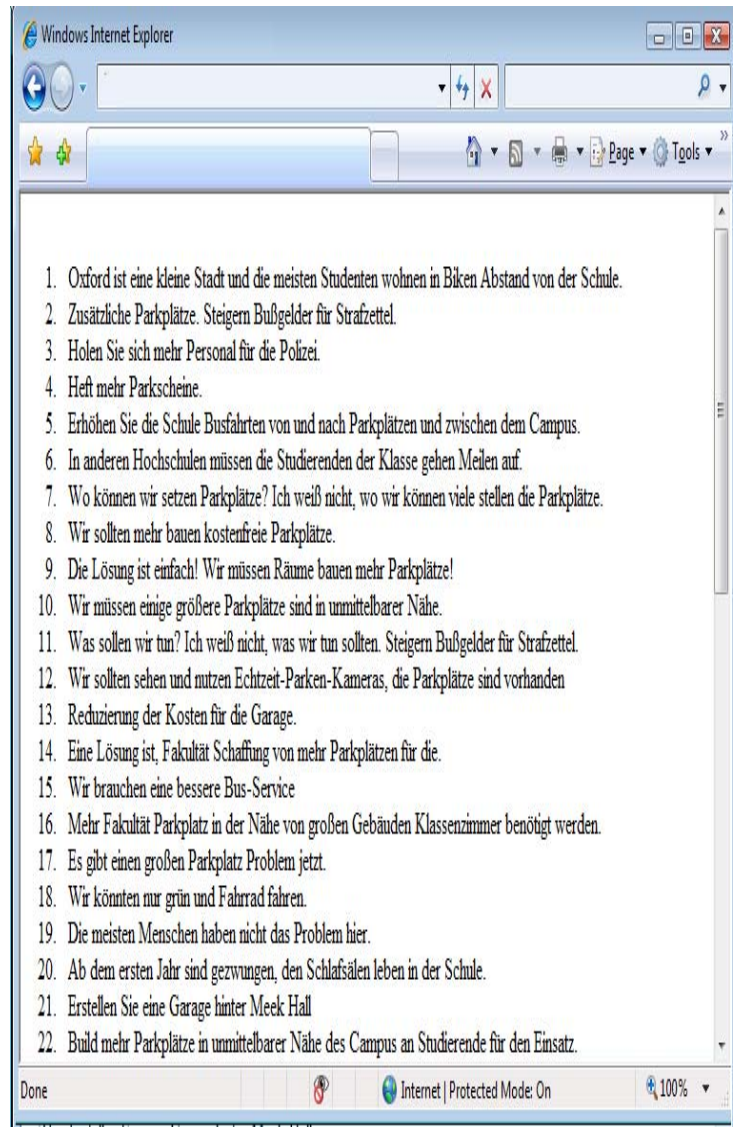

Some studies have shown that translation comprehension using Polyglot met the group members' requirements but this comprehension can vary by language combination, complexity of the comment text, and misspellings [3].

Although discussions have been conducted with multilingual, electronic meeting software and some meetings have been conducted using a single language with PDAs, to our knowledge, no multilingual groups have met using cellular devices. Smart devices have been capable of translating written and even interpreting oral comments, but this capability has not as yet been integrated with meeting software $[1,5,28]$.

To address this need, Polyglot was modified to fit the limited screen size of a Pocket PC, and Figure 2 shows a group member reading parking-problem comments in Spanish. Other than the reduced screen size and the greater difficulty entering comments, the software functions on a smart device exactly like its desktop counterpart. 
Volume XII, No. 1, pp. 16-22, 2011

Figure 2: User reading meeting comments in Spanish with a Pocket PC emulator Web browser

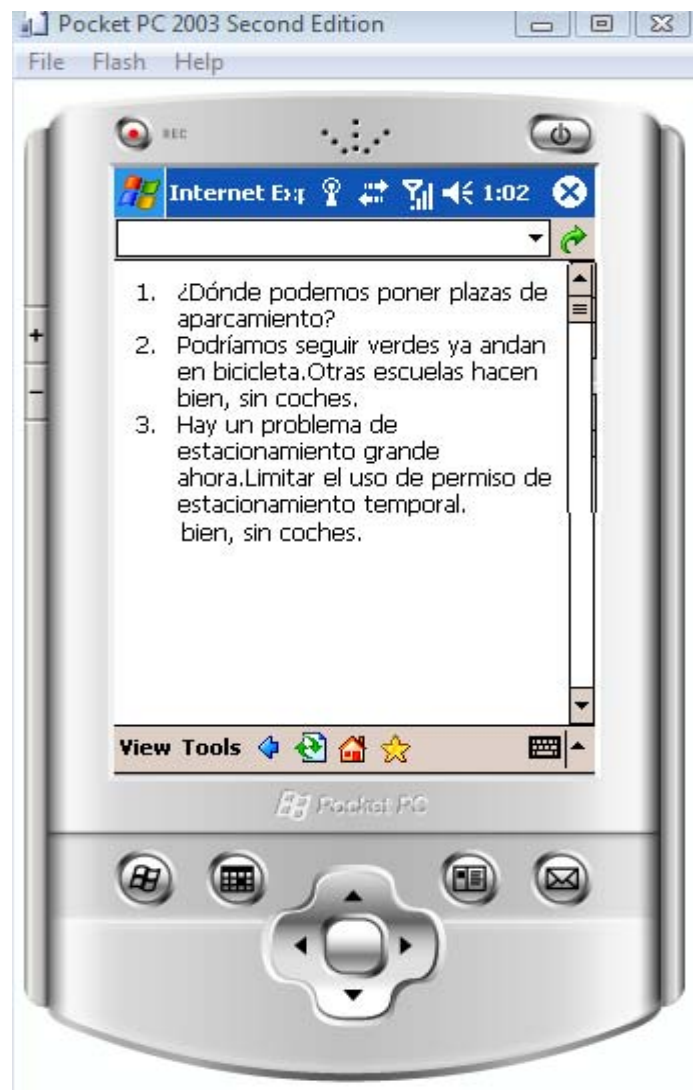

HYPOTHESES DEVELOPMENT

To explore how groups might meet with a cellular device as compared to a static, desktop system, we decided to study a meeting using Internet Explorer on Microsoft's Pocket PC emulator (hereafter designated PDA) versus on a desktop. Thus, the meetings used the same computers and keyboards, and the only difference was screen size for entering and viewing comments. With this restriction, we were able to eliminate other variables that could affect perceptions of usefulness, ease of use, and comprehension.

PDA ease of use and usefulness are strong determinants of successful utilization [9]. On desktop PC's, screen diagonals vary from 14" on up, a Pocket PC screen diagonal is about 3.8", and a smartphone screen diagonal can be up to 4.8" [24]. In addition, keyboard sizes are typically smaller for smart devices. Thus, there is greater difficulty entering and reading text with smaller devices [12].

Prior studies of users interacting with reduced screen sizes have been mixed. In one study [23], users interacting with screens showing only 15 lines of text were $50 \%$ less effective in completing tasks using a Web browser than those who were able to see 30 lines of text. However, another study [17] showed that users' ability to read and understand information was not adversely affected even when only a few lines of text were shown. A third study showed that the optimal height was just 4 lines of text [18]. There were no significant improvements in comprehension when the display height was increased to 20 lines and reading times were only $9 \%$ slower on the small screen.

Given these results, we propose the following hypothesis: 
Volume XII, No. 1, pp. 16-22, 2011

H1: There will be no significant difference between the PDA and desktop groups in terms of ease of use.

Translation comprehension can also affect a user's perceptions of the multilingual meeting software usefulness, and there could be a lower limit of acceptability [14,30]. Some have suggested that an acceptable accuracy is only $40 \%$ [13], while others have suggested at least $80 \%$ is necessary in a meeting [19].

Screen size might not affect a user's perceptions of understandability, however. In one study (Dillon et al., 1990), subjects were presented with 3,500 words in either a 20- or 60-line display window and were asked to summarize the main points. The study found that the comprehension rates on the smaller screen were as good as those on the larger. Although 20 lines of text is much larger than the display window of a PDA, most comments in an electronic meeting are only a few lines long. Thus, we suggest:

H2: There will be no significant difference between the PDA and desktop groups in terms of translated comment comprehension.

Finally, if there is no difference in ease of use or comprehension, there should also be no difference in perceived usability.

H3: There will be no significant difference between the PDA and desktop groups in terms of system usability.

\section{EXPERIMENT}

A study was conducted with 39 undergraduate Business students at a university in the southern United States, and these participants were randomly distributed in four groups with sizes of 10, 10, 10 and 9 .

Although any of 57 languages supported by Polyglot could have been used, we chose German and Spanish for the languages of discussion. As the students were not familiar with either German or Spanish, they were provided a Microsoft Word document with German and Spanish comments to copy and paste into the multilingual meeting software. These comments were originally typed in English from a previous electronic meeting focused on ways to solve the parking problem on campus and were then translated to German and Spanish by a human expert.

In 5 minutes, students copied and pasted the sentences into Polyglot running on Internet Explorer. The first and the second group ran the Web browser on the full desktop, while the third and the fourth groups ran the browser under the Pocket PC emulator, thus constricting the space available to enter and read comments. After entering the foreign comments, the students selected English as the language of communication and read the translations provided automatically by the system. Finally, the students completed a questionnaire asking them to evaluate their perceptions of translation comprehension, software ease of use, and software usability for a meeting.

Cronbach's alpha values were calculated to test the reliability of questionnaire constructs, and comprehension (0.871), ease of use (0.911), and usefulness (0.935) each met the minimum criterion of $0.7[15,26]$.

Table 1: Variable summary

\begin{tabular}{|l|l|l|l|l|}
\hline & \multicolumn{2}{|l|}{ PDA } & \multicolumn{2}{l|}{ Desktop } \\
\hline & Mean & $\begin{array}{l}\text { Std } \\
\text { Dev }\end{array}$ & Mean & $\begin{array}{l}\text { Std } \\
\text { Dev }\end{array}$ \\
\hline Comp & 5.44 & 1.09 & 6.02 & 1.05 \\
\hline Ease & 5.15 & 1.37 & 5.38 & 1.49 \\
\hline Usability & 4.87 & 1.33 & 5.28 & 1.54 \\
\hline
\end{tabular}

All means significantly different from neutral value of 4 at $\alpha=0.05$ 
Table 1 shows summary results for the variables in the study. In both treatments, students were able to comprehend the translations to English and believed each system was easy to use and useful. We found there was no significant difference between the two treatments in terms of comprehension $(F=3.957, p=0.054)$, ease-of-use $(F=0.840, p=$ $0.500)$, and usability $(\mathrm{F}=1.098, \mathrm{p}=0.372)$. Therefore, we cannot reject $\mathrm{H} 1, \mathrm{H} 2$, or $\mathrm{H} 3$.

In addition, a correlation analysis showed that comprehension was significantly associated with ease of use $(\mathrm{R}=$ $0.518, \mathrm{p}<0.001)$ and usability $(\mathrm{R}=0.333, \mathrm{p}=0.038)$, and ease of use was significantly associated with usability $(\mathrm{R}$ $=0.562, \mathrm{p}<0.001)$.

After the experiment was conducted, two evaluators were asked to rate their comprehension of individual comments using the same three scales, as the students were asked to evaluate comprehension only overall. There was strong agreement between the two evaluators as inter-rater reliability was found to be 0.813 , considered good [21, $\mathrm{p} 231]$. The average comprehension ratings were 6.71 and 6.67 on a 1 to 7 scale, each significantly above the neutral value of 4 , and there appeared to be no comment that was not understood.

\section{CONCLUSION}

The workforce is becoming increasingly cellular as more employees use smart devices in business. Although the screen size and bandwidth of cellular devices connected to the Internet are not equivalent to desktop computers connected to high-speed lines [29], these differences might not matter for cellular meetings.

This research investigated groups using multilingual meeting software running on either a full computer desktop or on a PDA emulator approximately the same size as an actual device. In both cases, students were allowed to copy and paste German and Spanish comments using a keyboard, and the only difference between the two treatments was the text area for reading and typing comments. Results showed that group members were able to comprehend the comment translations to English equally well, and they did not think there was a significant difference in ease of use or usability. Therefore, we conclude that cellular, multilingual meetings could be just as effective and efficient as equivalent, face-to-face meetings using desktop computers.

Perhaps the most important limitation to the study is that differences in typing capabilities were not investigated. That is, in both cases, students used a full-sized keyboard for entering comments, but it is more difficult to enter text on an actual PDA, even though many college students are accomplished with texting.

The second limitation is that only two languages were used for input (German and Spanish) and one was used for evaluation (English). Comprehension of translations between other language pairs (e.g., Korean to Hindi) could be different.

Third, group members in the two electronic meetings used pre-recorded comments with no spelling errors. The presence of errors would likely decrease the translation accuracy.

Obviously, future research should focus on groups using actual PDAs in geographically dispersed and face-to-face environments to further investigate the feasibility of cellular meetings. In addition, the research should be duplicated using emulators or actual devices with even smaller screen displays, such as that provided by cellular phones.

\section{REFERENCES}

1. Agrawal, A. and Chandak, M. (2007). Mobile interface for domain specific machine translation using short messaging service. Proceedings of the $4^{\text {th }}$ International Conference on Information Technology, 957-958.

2. Aiken, M. (2008). Multilingual collaboration in electronic meetings. Encyclopedia of E-Collaboration, Kock, N. (ed). IGI Global: Hershey, Pennsylvania, 457-462.

3. Aiken, M. and Balan, S. (2011). An analysis of Google Translate accuracy, Translation Journal, 16(2).

4. Aiken, M. and Ghosh, K. (2009). Automatic translation in multilingual business meetings. Industrial Management \& Data Systems, 109(7), 916-925. 
Volume XII, No. 1, pp. 16-22, 2011

5. Aiken, M., Park, M., and Balan, S. (2010a). DGL: A prototype system for machine interpretation. Translation Journal, 14(3).

6. Aiken, M., Park, M., and Lindblom, T. (2010b). Integrating machine translation with group support systems. International Journal of Business and Management, 5(5), 25-35.

7. Aiken, M. and Vanjani, M. (2009). Polyglot: A multilingual group support system. Issues in Information Systems, 10(2), 101-106.

8. Aiken, M., Wang, J., Gu, L., and Paolillo, J. (2011). An exploratory study of how technology supports communication in multilingual groups. International Journal of e-Collaboration, 7(1), 17-29.

9. Arninga, K. and Ziefle, M. (2007). Understanding age differences in PDA acceptance and performance. Computers in Human Behavior. 23(6), 2904-2927.

10. Antunes, P. and Costa, C. (2002). Handheld CSCW in the meeting environment. Groupware: Design, Implementation, and Use: Lecture Notes in Computer Science, 2440, 261-277.

11. Bravo, C. and García, P. (2006). A system to support collaborative mobile electronic meetings. Cooperative Design, Visualization, and Engineering: Lecture Notes in Computer Science, 4101, 200-210.

12. Buchanan, G., Farrant, S., Jones, M., Thimbleby, H., Marsden, and G., Pazzani, M. (2001). Improving mobile internet usability. Proceedings of the 10th International Conference on World Wide Web, ACM: New York, NY, USA.

13. Caulfield, H. and Reeder, F. (2001). Evaluation of endogenous systems. MITRE Technical Papers. Retrieved from http://mitre-corp.org.

14. Chuan-Chuan, J. and Lu, H. (2000). Towards an understanding of the behavioural intention to use a web site. International Journal of Information Management, 20(3), 197-208.

15. Cronbach, L.J. (1970) Essentials of Psychological Testing, Harper Collins: New York, NY.

16. Davis, R., Landay, J., Chen, V., Huang, J., Lee, R., Li, F., Lin, J., Morrey, C., Schleimer, B., Price, M., and Schilit, B. (1999). NotePals: Lightweight note sharing by the group, for the group. Proceedings of the SIGCHI conference on Human factors in computing systems. ACM: New York, NY.

17. Dillon, A., Richardson, J., and McKnight, C. (1990). The effect of display size and text splitting on reading lengthy text from the screen. Behaviour and Information Technology, 9(3), 215-227.

18. Duchnicky, R. and Kolers, P. (1983). Readability of text scrolled on visual display terminals as a function of window size. Human Factors, 25, 683-692.

19. Fügen, C., Waibel, A., and Kolss, M. (2007). Simultaneous translation of lectures and speeches. Machine Translation, 21(4), 209-252

20. Gartner (2010). Gartner highlights key predictions for IT organizations and users in 2010 and beyond. Retrieved from http://www.gartner.com/it/page.jsp?id=1278413

21. George, D. and Mallery, P. (2003). SPSS for Windows Step by Step: A Simple Guide and Reference. 11.0 update (4th ed.). Boston: Allyn and Bacon.

22. ITU (2009). Measuring the Information Society - The ICT Development Index, 2009 Edition. Retrieved from http://www.itu.int/ITU-D/ict/publications/idi/2009/index.html

23. Jones, M., Marsden, G., Mohd-Nasir, N., Boone, K., and Buchanan, G. (1999). Improving Web interaction on small displays. Computer Networks, 31(11-16), 1129-1137.

24. Murph, D. (2010). Acer reveals 4.8-inch Android smartphone with $1024 \times 480$ screen resolution. Retrieved from http://www.engadget.com/2010/11/23/acer-reveals-4-8-inch-android-smartphone-with-1024x480-screen-re/

25. Myers, B., Stiel, H., Gargiulo, R. (1998). Collaboration using multiple PDAs connected to a PC. Proceedings of the 1998 ACM Conference on Computer Supported Cooperative Work. ACM: New York, NY.

26. Nunamaker, J., Dennis, A., Valacich, J., Vogel, D., \& George, J. (1991). Electronic meeting systems to support group work. Communications of the ACM 34(7), 30-39.

27. Nunnally, J.C. (1978) Psychometric Theory, Donnelley \& Sons: New York, NY.

28. Samanta, S., Woods, J., and Ghanbari, M. (2011). Automatic language translation: An enhancement to the mobile messaging services. International Journal of Technology and Human Interaction, 7(1), 1-18.

29. Uther, M. (2002). Mobile Internet usability: What can 'mobile learning' learn from the past? IEEE International Workshop on Wireless and Mobile Technologies in Education, 174-176.

30. Wixom, B. and Todd, P. (2005). A theoretical integration of user satisfaction and technology acceptance. Information Systems Research, 16(1), 85-102. 
31. Zurita, G., Antunes, P., Baloian, N., Carriço, L., Baytelman, F., and Sá, M. (2008). Using PDAs in meetings: Patterns, architecture, and components. Journal of Universal Computer Science, 14(1), 123-147.

32. Zurita, G., Antunes, P., Carriço, L., Baytelman, F., Sá, M., and Baloian, N. (2006). Analyzing the roles of PDA in meeting scenarios. Groupware: Design, Implementation, and Use: Lecture Notes in Computer Science, 4154, 364-380.

33. Zurita, G. and Baloian, N. (2005). Handheld-based electronic meeting support. Groupware: Design, Implementation, and Use: Lecture Notes in Computer Science, 3706, 341-350. 